\title{
UNDERSTANDING DISCOUNT RATES UNDER SFAS 87
}

Frieda A. Bayer, Accounting, North Texas State University

\begin{abstract}
FASB has redefined the role of the accountant in employers' accounting for pensions. This paper reviews the process through which the accountant defines and applies the settlement rate under SFAS 87. An example illustrates the potential impact on income and the balance sheet of alternative rates. SFAS 87 guidelines regarding acceptable rates are examined to demonstrate the degree of flexibility still existing in the selection of an appropriate discount rate.
\end{abstract}

\section{INTRODUCTION}

In December of 1985, the Financial Accounting Standards Board issued Statement of Financial Accounting Standards No. 87 (SFAS 87), "Employers' Accounting for Pensions." Now mandatory for income reporting purposes, SFAS 87 defines generally accepted accounting principles (GAAP) for employers sponsoring defined benefit pension plans. Previous standards have been criticized for permitting too much flexibility and too little comparability in the computation of pension expense. Statement users have found it difficult to interpret variation in expense among companies or between years for the same company, i.e., are differences due to economic differences or the choice of computation methods? SFAS 87 narrows the accounting choices made by a company in addition to requiring more detailed disclosure relative to the financial statement amounts. SFAS 87 also will require reporting of additional liabilities previously unrecognized.

One significant aspect of SFAS 87 involves new criteria for the selection of the discount or "settlement" rate. This rate is applied in the calculation of the net periodic pension cost and any liability defined under SFAS 87. Understanding the process of determining the discount rate is important because of the sensitivity of firm income and the balance sheet pension liability to even minor variations in the rate applied. For example, under certain conditions, a one percentage point increase in the discount rate may decrease pension cost by 33 percent. If pension cost is large relative to income, this decrease would result in a material increase in reported income.

Prior to SFAS 87, the actuary advising the employer has determined the discount rate via his primary role in the selection of a discount rate to be used in funding the plan. SFAS 87 carefully distinguishes between funding the plan and accounting for it. Employers must now make the important decision regarding what discount or "settlement" rate to use to calculate accounting costs. Thus, the primary burden will shift from the actuary to the accountant. To help in the decision-making process, this paper reviews the process through which the discount rate is applied under SFAS 87, the potential impact on income and the balance sheet of alternative rates, and SFAS 87 guidelines regarding the range of acceptable rates. The paper concludes that considerable flexibility in the selection of the discount rate still exists under SFAS 87 and that, because of the significant impact of the discount rate on pension expense and the related liability, the accountant can maintain a degree of control over his 
firm's net income and balance sheet despite the new guidelines.

\section{THE DISCOUNT RATE IN SFAS 87 CALCULATIONS}

Under SFAS 87, the discount rate is applied in the calculation of the net periodic pension cost (NPPC) and any additional liability defined. NPPC consists of four major elements as listed in table 1. The discount rate is employed in the calculation of the following NPPC components: service cost, interest cost, amortization of the net gain/loss from earlier periods, amortization of unrecognized prior service costs, and amortization of the unrecognized net obligation/asset defined at the date of SFAS 87 adoption. The discount rate also affects the calculation of the unfunded accumulated benefit obligation (UABO) which under SFAS 87 must be reported on the balance sheet as a liability offset by an intangible asset or a debit to stockowner's equity. The following discussion describes the process through which the discount rate affects the NPPC and the balance sheet liability with particular emphasis on the impact of a change in discount rate on these

TABLE 1

COMPONENTS OF NET PERIODIC PENSION COST (NPPC)
A. Service cost (SC)
$\$ X X X$
B. Interest cost (IC)
$x X$
C. Actual return on assets
$(X X)$
D. Amortization of:
1. Net asset (gain) or loss during
the period deferred for later
recognition (in effect, an offset
or a supplement to the actual return
on assets)
$(X X)$ or $X X$

2. Net (gain) or

loss from earlier periods $\quad(X X)$ or $X X$

3. Unrecognized prior

service costs

$x x$

4. Unrecognized net obligation (or net asset) existing at date of SFAS 87 adoption

$X X$ or $(X X)$

E. NPPC

$\$ X X X$ 
elements of the income statement and the balance sheet.

\section{THE DISCOUNT RATE AND NPPC}

Service cost (SC) and interest cost (IC) are both defined in terms of the projected benefit obligation (PBO). The $\mathrm{PBO}$ is plan specific and is the actuarial present value as of a given date of all benefits attributed by the pension benefit formula to employee service rendered prior to that date. It is an "actuarial" present value measurement because it incorporates a number of judgmental variables (termed actuarial assumptions) related to the future, including mortality, employee withdrawal, salary, retirement and disability arates, as well as the discount rate.

The resultant PBO varies greatly depending on the assumptions made. Figure 1 illustrates this potential vari-

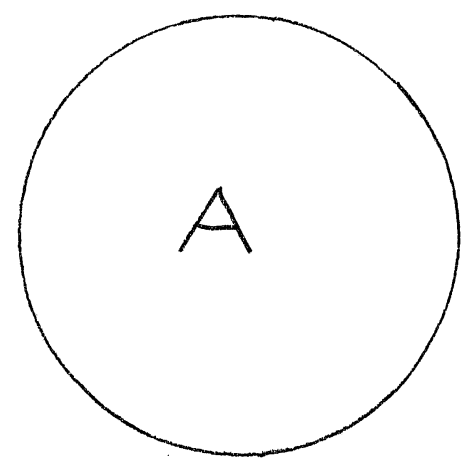

1. Lowest mortality among active and retired employees

2. Lowest withdrawal among active employees

3. Highest pay raises

4. Lowest disability rates

5. Most retirements

6. Lowest discount rate

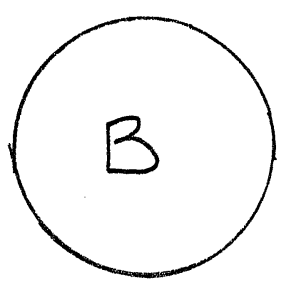

1. Highest mortality among active and retired employees

2. Highest withdrawal among active employees

3. Lowest pay raises

4. Highest disability rates

5. Fewest retirements

6. Highest discount rate 
ability using circles to represent PBO's. Circle A represents a larger $\mathrm{PBO}$ than circle B. These two circles may result from the calculation of the $\mathrm{PBO}$ for the same plan and the same employee group but with different judgments as to future mortality, employee withdrawal, salary increases, retirement and disability rates, and discount rate. Figure 1 illustrates two extremes but any size circle between these extremes can result from a selection of a different combination of the five variables in the figure. SFAS 87 prescribes limits in the selection of the discount rate and the salary assumption and requires the use of explicit assumptions, i.e., each is selected individually as the best estimate of a particular future event (SFAS 87, para. 14). SFAS 87 does not prescribe guidelines for choosing the mortality, employee withdrawal or retirement/disability assumptions.

To demonstrate the effect of the discount rate on the $\mathrm{PBO}$, and there fore on the calculation of service cost and interest cost, a simple example will be used in which the only variable is the discount rate. Note how variability in discount rates affects these two costs, and how that impact is magnified when the discount period changes.

\section{ILLUSTRATION FOR DISCUSSION}

Initially, assume one employee (B. Glad) who began work on 1/1/X1 and at the end of 19X2 has three years to retirement. B. Glad earns a pension benefit of $\$ 12,000$ for each year of service, and the benefits vest immediately. The employee will live to retire and receive a lump sum payment at retirement $(12 / 31 / \mathrm{X} 5)$. There is no funding of the plan. The plan began $1 / 1 / \mathrm{X} 1$, and no credit is granted for past service. Figure 2 illustrates this example. Given such a situation what service cost and interest cost should be recognized in 19X2's income statement as NPPC?

FIGURE 2

ILLUSTRATION OF A PENSION BENEFIT

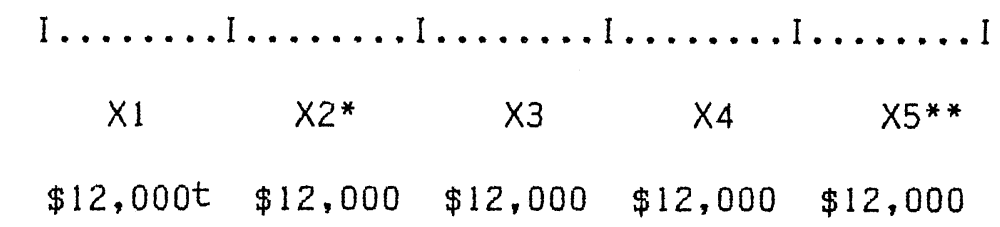

*19X2 is the year for which NPPC is being reported.

$* * 12 / 31 / / \times 5$ is the date of retirement.

the employee earns a $\$ 12,000$ benefit for each year of service payable as a lump sum on date of retirement. 
Under SFAS 87, the service cost for $19 \mathrm{X} 2$ is the present value of the benefit earned during 19X2, i.e., the present value of the difference between the benefit earned as of end of 19X2 (here, $\$ 24,000$ for two years of service -- X1 and X2) and the benefit earned as of the beginning of year 19X2 (\$12,000 for one year of service -- X1). To reflect the time value of money, the accountant discounts this amount $(\$ 12,000)$ for the three years remaining until the day of retirement $(12 / 31 / \mathrm{X} 5)$ when $\mathrm{B}$. Glad will receive her pension benefit as a lump sum. Using a discount rate of $10 \%$, the service cost equals:

$\operatorname{PV}(\mathrm{n}=3, \mathrm{i}=10 \%) \$ 12,000=\$ 9,016$

The accountant computes the interest cost by multiplying the $\mathrm{PBO}$ as of $1 / 1 / \mathrm{X} 2$ by the assumed discount rate, here $10 \%$. At the beginning of $19 \times 2$, B. Glad had worked one year and the PBO equals:

$\mathrm{PV}(\mathrm{n}=4, \mathrm{i}=10 \%) \$ 12,000=\$ 8,196$

Multiplying $\$ 8,196$ by a $10 \%$ discount rate yields an interest cost of $\$ 820$. For $19 \times 2$, the sum of the service cost and interest cost at a $10 \%$ discount rate is $\$ 9,836$.

\section{IMPACTOFALTERNATIVEDISCOUNT RATES AND DISCOUNT PERIODS}

What effect does a change in discount rate have on SC and IC? Table 2 demonstrates this phenomenon. When a higher discount rate is selected, the sum of the SC and IC components declines at a rate of approximately $4 \%$ for a two percentage point increase in the discount rate. It is clear, then, that all things equal, the higher the discount rate, the less the charge to income (assuming a constant discount period).

The relationship is magnified when the discount period lengthens. Let us assume a younger employee, I. M. Younger, who also began work on 1/1-
/X1 and earns benefits under the same pension plan provisions as B. Glad. However, Younger will work 23 more years before retiring. Table 2 illustrates this situation also. The differences in SC and IC under alternative discount rate assumptions are more pronounced -- $33 \%$ for a 2 percentage point increase in discount rate. Although each pension plan is unique, it can generally be assumed that a change in discount rate will have a more dramatic effect over a longer discount period. Therefore, the effect on income from a change in discount rate will be greater for a plan with participants who average 23 years to retirement rather than 3 years. Generally then, the younger the work force, the greater the impact of alternative discount rates, all other things equal.

\section{EFFECT OF DISCOUNT RATE ON OTHER COMPONENTS OF NPPC}

The NPPC includes the amortization of net gains or losses from earlier periods (D2 on table 1). Elements of these gains or losses include a change in the PBO resulting from experience different from that assumed and from changes in assumptions (SFAS 87, para. 29). If the discount rate is changed, the resulting effect on the PBO will be included as part of the unrecognized net gain (if the discount rate increases) or loss (if the discount rate decreases) subject to amortization. The effect on the NPPC of this change in discount rate is minimized because of the corridor provisions of SFAS 87, i.e., only if the unrecognized gains/losses exceed $10 \%$ of the greater of the PBO or the market-related value of assets at the beginning of the year will a portion of the gains/losses be recognized.

To illustrate the above, return to the example represented in figure 2 . Assume that the 19X1 calculation of the NPPC incorporated a discount rate of $8 \%$. Now, at the beginning of $19 \times 2$, the accountant decides that $10 \%$ is a more appropriate rate. The accountant 
TABLE 2

SERVICE AND INTEREST COST

UNDER

ALTERNATIVE DISCOUNT RATES AND DISCOUNT PERIODS

Years to Retirement

3

\begin{tabular}{|c|c|c|c|c|c|c|c|c|c|}
\hline $\begin{array}{l}\text { Discount } \\
\text { Rate: }\end{array}$ & SC & IC & Total & Diff & $\%$ & SC & IC & Total & Diff \\
\hline $8 \%$ & 9,526 & 706 & 10,232 & & & 2044 & 151 & 2195 & \\
\hline $10 \%$ & 9,016 & 820 & $9,836^{>}$ & 396 & 4 & 1340 & 134 & $1474^{>}$ & 721 \\
\hline $12 \%$ & 8,541 & 915 & $9,456^{>}$ & 380 & 4 & 885 & 106 & $991^{>}$ & 483 \\
\hline
\end{tabular}

calculates the $\mathrm{PBO}$ at $1 / 1 / \mathrm{X} 2$ under both alternative rates. Under an $8 \%$ discount rate, the PBO would be $\$ 8,820$ (PV $(\mathrm{n}=4, \mathrm{i}=8 \%) \$ 12,000)$. Alternatively, the PBO would be $\$ 8,196$ (PV $(n=4$, $\mathrm{i}=10 \%) \$ 12,000)$ if a $10 \%$ rate had been used. The difference of $\$ 624$ represents an unrecognized gain. Since the difference is less than $10 \%$ of the PBO as of $1 / 1 / \mathrm{X} 2(\$ 8,196)$, none of the gain is recognized. If the gain had exceeded the corridor boundaries, it would have been amortized over the service lives of the plan participants.

The discount rate also enters the calculation of the NPPC through the estimation of the amount of prior service cost (PSC) to be amortized due to a plan amendment (see D3 on table 1). SFAS 87 defines the PSC as the increase in the PBO at the date of the amendment (SFAS 87, para. 25). In our example, a plan amendment on $1 / 1 / \mathrm{X} 2$ might retroactively increase B. Glad's benefits by $\$ 2,000$ per year. At that point, the increase in PBO would be defined as the present value of $\$ 2,000$ (for 19X1), discounted four periods using the discount rate appropriate at that measurement date. This new addition to the PSC will never be recalculated so its size will depend upon the discount rate selected on the date of plan amendment. The cost of retroactive benefits is expensed prospectively over the service lives of the plan participants affected by the amendment. The impact on the NPPC will be inversely related to the magnitude of the discount rate used to determine PSC.

The final component of NPPC to be affected by the discount rate assumption is the amortization of the unrecognized net obligation (or net asset) existing at date of SFAS 87 adoption (D4 in table 1). At the beginning of the fiscal year in which SFAS 87 is adopted, the accountant must determine 
the PBO as well as the fair value of plan assets (adjusted for accrued or prepaid pension cost). The difference between the PBO and plan assets represents an unrecognized net obligation or net asset which is amortized to the NPPC (SFAS 87, para. 77). Again, the selection of the discount rate is important because of its effect on the magnitude of the PBO. All things equal, a greater discount rate will result in a smaller increase in the NPPC or an actual reduction in the NPPC over the amortization period of this component.

\section{EFFECT OF DISCOUNT RATE ON UABO}

Not only does the discount rate affect the level of the NPPC each period but it also affects the calculation of the unfunded accumulated benefit obligation (UABO) which under SFAS 87 must be reported on the balance sheet (after 1989) as a liability offset by an intangible asset or a reduction in stockholders' equity. The UABO is based on measurement at financial statement date of the accumulated benefit obligation $(\mathrm{ABO})$. The $\mathrm{ABO}$ differs from the $\mathrm{PBO}$ in that it includes no assumption of future salary increases. In our example, because the plan benefit was not based upon salary, the PBO equals the ABO. However, in a pay-related plan, this equality would not exist. In the calculation of the SC component of the NPPC, the accountant focuses on the incremental change in PBO during the year. To measure the UABO the accountant focuses on all benefits earned as of the end of the reporting year and discounts that amount for the years remaining until retirement before comparing the value of benefits to the assets available. If the benefits exceed the assets, a liability exists. Thus, the balance sheet liability will also vary considerably depending upon the discount rate assumed.

\section{ASSUMED DISCOUNT RATE -- FASB GUIDELINES}

Given the significant impact of the discount rate on income and financial position under SFAS 87, what guidelines are provided in the statement for its determination? SFAS 87 defines the discount rate as an approximation of the rate at which pension benefits could be settled as of a given measurement date. In other words, assume the plan sponsor has one employee due to retire in 10 years to whom will be paid a monthly pension benefit of $\$ 1,000$. The employee is expected to live 5 years after retirement. The plan sponsor wants to purchase a contract to provide that deferred annuity. An insurance company is contacted and agrees to a contract for a purchase price of $\$ 25,000$. The discount rate is that rate which reduces the stream of $\$ 1,000$ payments commencing in 10 years and extending 5 years thereafter to a present value of $\$ 25,000$. The rate is chosen independent of the asset mix or investment plan of the pension fund.

The measurement date is an important consideration in determining the discount rate under SFAS 87. For a firm with a $12 / 31$ year end, the NPPC calculation requires a January 1 measurement date (unless a plan amendment or other significant event occurs during the 19X1 period triggering a new plan valuation). The calculation of the obligation (projected, accrued and vested benefits) is based upon a December 31 measurement date. As is illustrated below, there may be a measurable difference in the two rates.

For a given plan, the sponsor must estimate a schedule of

benefit payouts for each year in the future beginning with the plan valuation date. Since interest rates in the market place vary depending upon the maturity date of the investment, the "discount rate" is actually a weighted average of a series of rates reflecting - various obligation maturities. Figure 3 illustrates the calculation of a weighted average discount rate assuming the last participant dies at the end of year 5 . 


\section{FIGURE 3}

\section{STREAM OF BENEFIT PAY-OUTS}

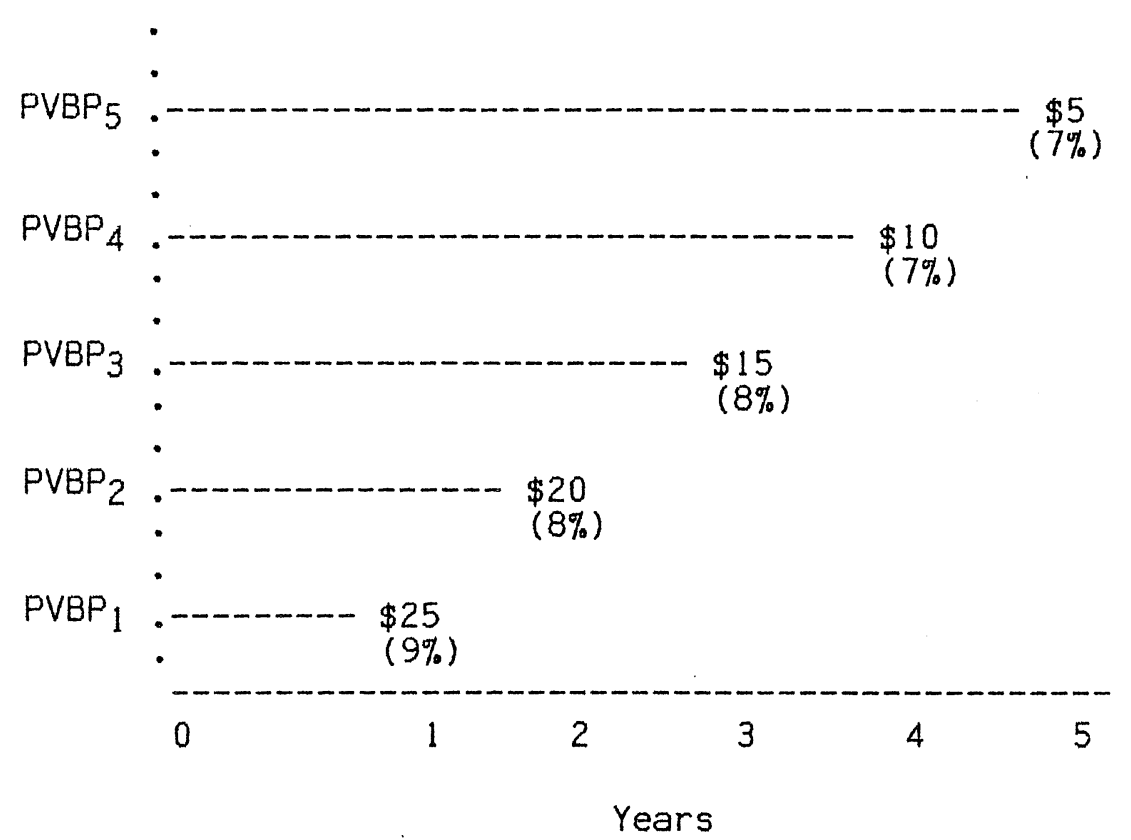

Weighted Average Discount Rate

PV of Payouts

PV $(n=5, i=7 \%) \quad \$ 5=3.6$
PV $(n=4, i=7 \%) \quad \$ 10=7.6$
PV $(n=3, i=8 \%) \quad \$ 15=11.9$
PV $(n=2, i=8 \%) \$ 20=17.1$
PV $(n=1, i=9 \%) \quad \$ 25=22.9$

63.1
We ight

$\begin{array}{lll}X & 7 \% & = \\ X & 7 \% & =.25 \\ X & 8 \% & =.53 \\ X & 8 \% & =1.35 \\ X & 9 \% & =2.06\end{array}$

5.17

\footnotetext{
5.2 
The weighted-average rate will vary for different plans depending upon the age distribution of the plan participants which will influence the schedule of benefit pay-outs.

The theoretical discount rate described above is not directly observable, i.e., no annuity contracts are actually purchased. Therefore, SFAS 87 suggests that three alternative sources of information be used: (1) current prices of similar, recently purchased annuity contracts, (2) current annuity rates published by the Pension Benefit Guaranty Corporation (PBGC), and (3) "rates of return on high-quality fixed-income investments currently available and expected to be available during the period to maturity of the pension benefits" [SFAS 87, para. 44.].

\section{CURRENT PRICES OF ANNUITY CONTRACTS}

Since no annuity contracts are actually purchased, the purchase price of other similar annuity contracts for which bids have been received can be used. Two probable sources of this information would be plan sponsor experience or the plan's actuary. If the sponsor itself had recently purchased an annuity contract or if the actuary had participated in such a purchase for another of his clients, this information could be used to approximate a discount rate. According to the American Council of Life Insurance, insurance settlement rates are not published so secondary information would not be available to the employer. The market for these contracts is very competitive and the rates change daily. In using actual annuity contract rates as surrogate rates, the employer must use comparable payout periods and must remove the profit margin, expense loadings, and contingency margins built into the purchase price. With these limitations, this method of estimating a discount rate is unlikely to be used except to provide a ceiling on a range of estimated discount rates.

\section{PBGC RATES}

Under the Employee Retirement Income Security Act of 1974 (ERISA), as amended, the PBGC established a method of determining the value of plan benefits at point of termination for non-multiemployer pension plans covered by ERISA. The value of plan benefits is compared to plan assets to determine the amount of any plan asset insufficiency or excess. PBGC publishes interest rates periodically which can be used in this determination (Title 29, Ch. XXVI, Part 2619, Appendix B). The rates have varied from $8 \%$ in 1975 to $10.50 \%$ in 1982 to $8.75 \%$ in 1986 . Table 3 illustrates the change in PBGC rates using $1 / 1 / \mathrm{XX}$ data points. Given the movement in rates from year to year, it is apparent why it has been argued that SFAS 87 may lead to increased volatility. Recently, rates have been falling in response to investment yields in the market.

Of the three alternative approaches to determining a discount rate, adoption of the PBGC rates is the most conservative and the least costly approach to selecting a discount rate. FASB considered allowing only the use of PBGC rates but decided that "no readily available rates seemed fully suitable" (SFAS 87, para. 196). During a spring 1986 meeting of FASB, called to discussed SFAS 87 technical questions, discussants used terminology such as PBGC + 1 indicating that the PBGC rates would be valuable as a starting point in determining a usable discount rate with an adjustment made to correct for conservatism of the PBGC rate.

\section{HIGH-QUALITY FIXED-INCOME INVESTMENT RATES}

The third alternative rate acceptable under SFAS 87 is based upon yields on high-quality, fixed-income investments of various maturities (to match the benefit pay-out period). SFAS 87 includes U.S. Treasury Bills, 7 year bonds and 30 year bonds as examples. High 
TABLE 3

DISCOUNT RATES UNDER SFAS $87: 1975-1986$

\begin{tabular}{lccl}
\hline & & & \\
\hline & PBGC Rates & $\begin{array}{l}\text { Treasury } \\
\text { 20-Year } \\
\text { Bonds }\end{array}$ & $\begin{array}{l}\text { New Aa } \\
\text { Corporate } \\
\text { Bonds }\end{array}$ \\
1975 & 8.00 & 7.88 & 9.17 \\
1976 & 8.00 & 8.01 & 8.97 \\
1977 & 7.00 & 7.48 & 7.96 \\
1978 & 6.75 & 8.14 & 8.70 \\
1979 & 7.25 & 8.98 & 9.47 \\
1980 & 8.50 & 10.65 & 11.65 \\
1981 & 9.50 & 12.29 & 14.01 \\
1982 & 10.50 & 14.57 & 16.34 \\
1983 & 10.00 & 10.78 & 12.04 \\
1984 & 9.50 & 11.82 & 12.65 \\
1985 & 9.75 & 11.58 & 12.46 \\
1986 & 8.75 & 9.75 & 10.46 \\
& & & \\
\hline
\end{tabular}

quality is interpreted as Baa or better. Table 3 includes yields on two bond groups: New Aa Corporate bonds and 20-year Treasury bonds. Yields are available through investment services (e.g. Moody's Bond Record) and government publications.

OPPORTUNITIES FOR EMPLOYERS UNDER SFAS 87

FASB staff has indicated that a standardized procedure for selecting the discount rate is not required and that a change in "approach" from one period to another would not constitute a change in accounting principle, but a change in estimate. However, if a standardized procedure is adopted, e.g., a formula is used, e.g. (Moody's Aaa + PBGC rate) $/ 2$, and then subsequently changed, the employer must demonstrate how the new formula is better if the underlying circumstances have not 
changed. This approach suggests that more flexibility will exist in the selection of discount rates when an informal approach is applied. What range of rates will be possible under SFAS 87 ? With the exception of 1975 , the yields on the fixed-income, high-quality investments have been higher than the PBGC rates. The range of possible discount rates appears to narrow in periods of declining market interest rates. As interest rates increase, bond yields (and probably annuity purchase rates) increase faster than the PBGC rates and, therefore, the range expands. For example, during the 1980-82 period of rising interest rates, the range widened. In 1982, the difference between the Aa yield and the PBGC rate widened to almost 6 percentage points (16.$34 \%-10.50 \%$ ). Thus, SFAS 87 will reduce flexibility in periods of stable or gradually declining interest rates. During periods similar to $1975-1986$, the degree of flexibility in identifying a discount rate and therefore in determining NPPC will be significant.

Unfortunately, the process of es - timating the discount rate will not be costless. Since the FASB clearly separates the funding process from the expense recognition task, any additional analysis by a firm will add to its costs. To reduce costs, smaller firms may spend little time calculating a weighted-average discount rate, instead selecting as an alternative the PBGC rate or a PBGC adjusted by a constant factor, e.g. PBGC +1 . For the larger firms, the benefits associated with the opportunity to manage earnings and the balance sheet liability through the selection of a customized discount rate may exceed the costs of analysis. The potential benefits may justify additional computer analysis to explore short- and long-term effects of alternative weighted average discount rate scenarios on the NPPC and related balance sheet accounts. These firms may opt for a rate based upon high quality investments or current annuity contracts. Certainly, the accountant will be welladvised to review carefully the selection of the appropriate discount rate for the firm's particular facts and circumstances.

\section{REFERENCES}

Financial Accounting Standards Board, Employers' Accounting for Pensions (Stamford, Connecticut: FASB, December 1985). 